\title{
Protein BTG1
}

National Cancer Institute

\section{Source}

National Cancer Institute. Protein BT G1. NCI Thesaurus. Code C80104.

Protein BT G1 (171 aa, $\sim 19 \mathrm{kDa}$ ) is encoded by the human BT G1 gene. This protein is involved in cellular proliferation. 